\title{
Electrophoretic variation in the common mussel, mytilus edulis: random association of alleles at different loci
}

\author{
Mahmud Ahmad* and \\ Philip W. Hedrick $\dagger$
}

\author{
* Department of Biological Sciences, Quaid-i-Azam \\ University, Islamabad, Pakistan, and \\ $\dagger$ Division of Biological Sciences, University of Kansas, \\ Lawrence, Kansas 66045.
}

Unlike a sample of Mytilus edulis from North America (Mitton and Koehn, 1973), two large samples from the south coast of Wales (Pendine and Aberavon), did not show association of alleles at the functionally related $A p$ and $L a p$ loci. At Aberavon an additional five locus pairs were examined and only one ( Lap-Pgm) showed significant non-random association. However, even this association was not present when the sample was divided into different size classes, nor was it present in a composite sample from another area of the south coast of Wales (Gower).

\section{INTRODUCTION}

When considering genetic variation at a single locus, a number of statistical approaches have been suggested to determine whether the pattern of variation is consistent with neutrality (e.g., Ewens, 1977). In addition, the extent and pattern of association of alleles at different loci, gametic disequilibrium, has been suggested as a possible way to evaluate natural selection between loci (Lewontin, 1974). However, a number of other factors, such as gene flow, genetic drift, and genetic hitchhiking may cause substantial gametic disequilibrium (for a review see Hedrick, 1983), making it essential that other information about population parameters be known or that several independent populations be sampled.

Statistically significant non-random associations have really only been observed for tightly linked loci or for loci in highly-selfed or parthenogenetic organisms (e.g., Hedrick et al., 1978) with a few exceptions (e.g., Ennos, 1981; Hedrick, 1985; Turner, 1972). Another outstanding exception is the association of alleles at two apparently functionally related but unlinked ( $R$. Koehn, pers. comm.) enzyme loci, Ap (Aminopeptidase) and Lap (leucine aminopeptidase), in a sample from a North American population of the common mussel, Mytilus edulis (Mitton and Koehn, 1973). Based on the examination of potential causes of disequilibrium by Prout (1973),
Mitton and Koehn concluded that epistatic selection appeared to be the basis of this disequilibrium.

The main purpose of this study is to determine if there is non-random association between alleles at these loci in two other populations of Mytilus edulis off the coast of south Wales. Furthermore, in one population, two additional loci were examined and the pairwise associations between all pairs of loci were determined.

\section{MATERIALS AND METHODS}

The enzyme loci studied are Ap-1 (aminopeptidase), Lap-2 (leucine aminopeptidase), Pgm-2 (Phosphoglucomutase), and Phi (phosphohexos isomerase), hereinafter these systems have been referred to as Ap, Lap, Pgm, and Phi. The methods of electrophoretic assay of these systems have been described fully in Ahmad et al. (1977). Alleles for each locus are numbered in order of increasing anodal mobility. Different researchers have used different nomenclatures for alleles at these loci. By using data in the literature of allelic frequencies of the same population with different nomenclatures, homology of various alleles at $A p$ and Lap has been reasonably established. In order to clarify the relationships between these nomenclatures, we have given the allelic homologies for $A p$ and Lap using different nomenclatures in the Appendix. 
The populations sampled were at Pendine and Aberavon, geographically discrete populations, on the south Wales coast. At each location, 1000 individuals were collected from an approximate area of $1.5 \mathrm{~m}^{2}$ from a mid-intertidal position. In both populations, samples were analyzed for $A p$ and Lap and in Aberavon, individuals were also analyzed for loci Pgm and Phi.

The association of alleles at different loci was examined using the $\chi^{2}$ test for small expectations in contingency tables by Nass (1959). The degrees of freedom is given by $v$ and are not integers. However, when determining probability level of significance we ignored the fractional part of $v$. Although this is not a test of gametic disequilibrium per se, the $\chi^{2}$ values from contingency tables and $\chi^{2}$ tests for gametic disequilibrium using the approach of Hill (1974) are very highly correlated for biallelic loci (Hedrick, 1985). The contingency table analysis was used because it provides an approach by which small expectations are accommodated.

\section{RESULTS}

The allelic frequencies for the two loci surveyed at Pendine and the four loci at Aberavon are given in table 1 . Notice that all loci were quite polymorphic and had at least five alleles. The allelic frequencies of $A p$ and $L a p$ were not significantly different at the two locations. The $\chi^{2}$ values are $5 \cdot 60(p>0 \cdot 30,5$ degrees of freedom $)$ and $5 \cdot 60$ ( $p>0 \cdot 20,4$ d.f.) for $A p$ and Lap, respectively. These populations are very close to HardyWeinberg expectations (Ahmad et al., 1977).

The observed numbers of two-locus phenotypes for $A p$ and Lap are given in tables 2

Table 1 Allelic frequencies at enzyme loci in Mytilus edulis. In all cases 2000 genes (1000 individuals) were sampled

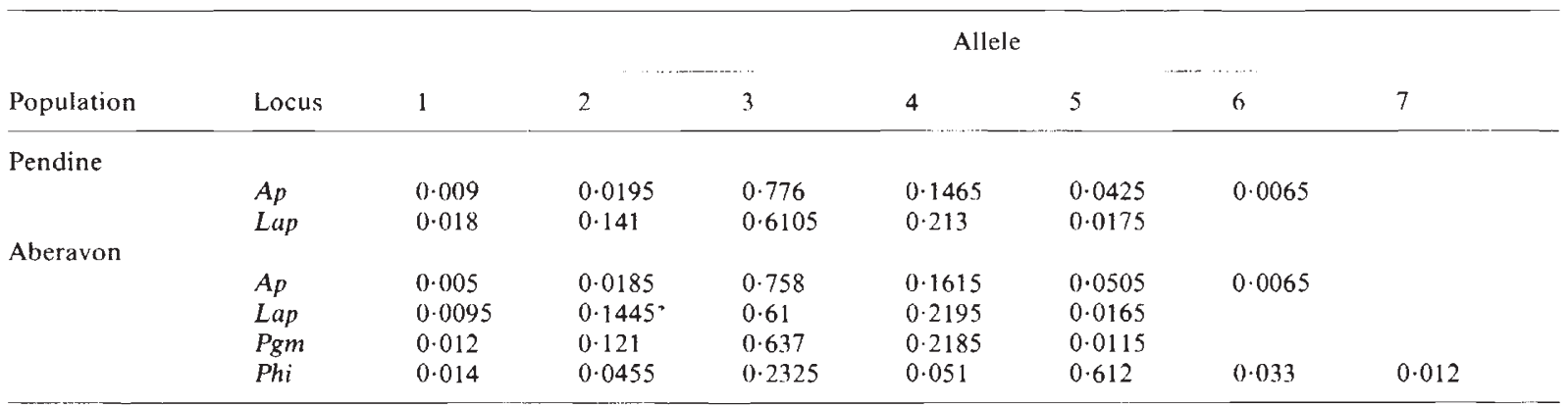

Table 2 The numbers of two-locus phenotypes of $A p$ and Lap at Pendine

\begin{tabular}{|c|c|c|c|c|c|c|c|c|c|c|c|c|c|c|c|c|}
\hline & & $\stackrel{1}{i}$ & $\frac{2}{2}$ & $\frac{3}{3}$ & $\stackrel{4}{4}$ & 5 & $\frac{1}{2}$ & $\frac{1}{3}$ & $\underset{\frac{1}{4}}{L a p}$ & $\frac{2}{3}$ & $\frac{2}{4}$ & $\frac{2}{5}$ & 3 & $\frac{3}{5}$ & $\frac{4}{5}$ & Total \\
\hline \multirow{17}{*}{$A p$} & $2 / 2$ & & & 1 & & & & & & & & & 1 & & & 2 \\
\hline & $3 / 3$ & & 18 & 240 & 34 & 1 & 2 & 14 & 7 & 87 & 36 & 3 & 143 & 13 & 3 & 601 \\
\hline & $4 / 4$ & & 3 & 7 & 2 & & & & & 6 & 1 & & 4 & & & 23 \\
\hline & $5 / 5$ & & & 3 & 1 & & & & & 1 & & 1 & & & & 6 \\
\hline & $1 / 3$ & 1 & & 4 & 2 & & & 1 & & 1 & 1 & & 4 & & & 14 \\
\hline & $1 / 4$ & & & 1 & 1 & & & & & & & & & & & 2 \\
\hline & $1 / 5$ & & & & & & & & & 1 & & & & & & 1 \\
\hline & $1 / 6$ & & & 1 & & & & & & & & & & & & 1 \\
\hline & $2 / 3$ & & & 9 & & & & & & 5 & 2 & & 13 & 1 & & 30 \\
\hline & $2 / 4$ & & 1 & & & 1 & & & & 2 & & & & & & 4 \\
\hline & $2 / 6$ & & & 1 & & & & & & & & & & & & 1 \\
\hline & $3 / 4$ & & 7 & 90 & 15 & & 1 & 4 & 2 & 36 & 9 & 1 & 61 & 6 & & 232 \\
\hline & $3 / 5$ & & 2 & 24 & 2 & & & 1 & & 16 & 3 & & 13 & 3 & & 64 \\
\hline & $3 / 6$ & & & 4 & & & 1 & & & 1 & & & 4 & & & 10 \\
\hline & $4 / 5$ & & 1 & 3 & 1 & & & & & & 1 & & 2 & & & 8 \\
\hline & $4 / 6$ & & & & & & & 1 & & & & & & & & 1 \\
\hline & Total & 1 & 32 & 388 & 58 & 2 & 4 & 21 & 9 & 156 & 53 & 5 & 245 & 23 & 3 & 1000 \\
\hline
\end{tabular}


Table 3 The numbers of two-locus phenotypes of $A p$ and Lap at Aberavon

\begin{tabular}{|c|c|c|c|c|c|c|c|c|c|c|c|c|c|c|}
\hline & & $\frac{2}{2}$ & $\frac{3}{3}$ & $\frac{4}{4}$ & $\frac{1}{2}$ & $\frac{1}{3}$ & $\frac{1}{4}$ & $\begin{array}{c}\text { Lap } \\
\frac{2}{3}\end{array}$ & $\frac{2}{4}$ & $\frac{2}{5}$ & $\frac{3}{4}$ & $\frac{3}{5}$ & $\frac{4}{5}$ & Total \\
\hline & $3 / 3$ & 23 & 234 & 35 & 1 & 6 & 3 & 97 & 32 & 4 & 140 & 8 & 5 & 588 \\
\hline & $4 / 4$ & & 11 & 2 & & 1 & & 4 & 2 & & 8 & & & 28 \\
\hline & $5 / 5$ & & 1 & & & & & & & & 1 & & & 2 \\
\hline & $1 / 3$ & & 5 & & & & & 1 & 1 & 1 & 1 & & & 9 \\
\hline & $1 / 4$ & & & & & & & & & & 1 & & & 1 \\
\hline \multirow[t]{10}{*}{$A p$} & $2 / 3$ & & 9 & 2 & & 1 & & 2 & & & 7 & & & 21 \\
\hline & $2 / 4$ & & 5 & 1 & & & & 3 & & & 1 & & & 10 \\
\hline & $2 / 5$ & 1 & 1 & 1 & & & & & & 1 & 1 & & & 5 \\
\hline & $2 / 6$ & & 1 & & & & & & & & & & & 1 \\
\hline & $3 / 4$ & 6 & 93 & 19 & 1 & 1 & 1 & 30 & 17 & 1 & 55 & 7 & & 231 \\
\hline & $3 / 5$ & 3 & 32 & 6 & & 2 & & 9 & 2 & & 11 & 3 & & 68 \\
\hline & $3 / 6$ & & 2 & & & 1 & & 1 & 1 & & 4 & 2 & & 11 \\
\hline & $4 / 5$ & 1 & 6 & 2 & & & 1 & 5 & 4 & & 4 & 1 & & 24 \\
\hline & $4 / 6$ & & & & & & & 1 & & & & & & 1 \\
\hline & Total & 34 & 400 & 68 & 2 & 12 & 5 & 153 & 59 & 7 & 234 & 21 & 5 & 1000 \\
\hline
\end{tabular}

and 3 for Pendine and Aberavon, respectively. (The term "phenotype" is used here because the phase of double heterozygotes is not known.) In both samples there were a large number of phenotypes present, 74 at Pendine and 75 at Aberavon. In nearly every case, the only two-locus phenotypes not observed were those with extremely low expectations.

Table 4 gives the $\chi^{2}$ values for these data on the first two lines and that for the other locus pairs at Aberavon below. First, note that the $\chi^{2}$ values of $A p-L a p$ are quite small, indicating that there is no evidence of association between alleles at these loci. Second, we also examined the Ap-Lap data using the allelic designations of Mitton and Koehn (1973)(see Appendix). In other words, we lumped alleles 1 and 2 at both loci into the $A p^{s}$ and $L a p^{s}$ alleles, lumped 4, 5 and 6 at the $A p$ locus into $A p^{f}$, and lumped 4 and 5 at the Lap locus into the $L a p^{f}$

Table 4 The $\chi^{2}$ values and their degrees of freedom and significance levels for the different pairs of loci

\begin{tabular}{lcrl}
\hline Locus pair & $\chi^{2}$ & $v$ & $p$ \\
\hline Ap-Lap (Pendine) & 16.31 & 12.12 & $>0.10$ \\
& $21.26^{*}$ & 19.47 & $>0.30$ \\
Ap-Lap (Aberavon) & 8.51 & 8.99 & $>0.30$ \\
& $9.26^{*}$ & 19.31 & $>0.95$ \\
Ap-Pgm & 5.10 & 7.84 & $>0.50$ \\
Ap-Phi & 4.35 & 6.10 & $>0.50$ \\
Lap-Pgm & 35.04 & 18.33 & $<0.01$ \\
Lap-Phi & 16.80 & 15.21 & $>0.30$ \\
Pgm-Phi & 10.62 & 13.26 & $>0.50$ \\
\hline
\end{tabular}

* Alleles lumped as in Mitton and Koehn (1973). allele. The $\chi^{2}$ values calculated in this manner indicate no association between alleles at the two loci (see table 4). Third, none of the other locus pairs are significant except for Lap-Pgm which is significant at the 0.01 level.

Further analysis of the significant Lap-Pgm association was done by dividing into four quartiles (sample sizes of 250 each) by size in increasing order. None of these size classes showed two-locus association (table 5), although in the case of size class II, the interlocus dependence almost reached the 5 per cent level of significance. To check this association further, other samples from various Mytilus edulis populations along the Gower coast with a total sample size of 1150 were pooled together (they were found to be homogeneous with respect to allelic and genotypic frequencies) and analyzed for two-locus association. This pooled sample (see table 5) also did not have significant association between the alleles at the two loci.

Table 5 The $\chi^{2}$ values and their degrees of freedom and significance levels for the Lap-Pgm locus pair for four class sizes from Aberavon and a composite sample from the Gower Coast

\begin{tabular}{lcrrl}
\hline & $\begin{array}{l}\text { Class } \\
\text { size }\end{array}$ & \multicolumn{1}{c}{$\chi^{2}$} & \multicolumn{1}{l}{$p$} \\
\hline Aberavon & I & 5.28 & 8.45 & $>0.70$ \\
& II & 15.58 & 8.47 & $\cong 0.05$ \\
& III & 13.95 & 14.57 & $>0.30$ \\
& IV & 14.90 & 15.32 & $>0.30$ \\
Gower Coast & & 7.00 & 7.89 & $>0.30$
\end{tabular}




\section{DISCUSSION}

The lack of gametic disequilibrium between these allozyme loci is hardly surprising considering that M. edulis consists of 14 pairs of chromosomes (Ahmad and Sparks, 1970) and the loci studied were mainly chosen for the ease with which they can be resolved electrophoretically without any knowledge of their linkage relationship. As stated before, nearly all significant cases of gametic disequilibrium reported in outbreeding organisms so far heve been between linked loci. Although theoretically it may be possible for loci not closely linked or loci situated on different chromosomes to show non-random associations due to selection, the magnitude of epistasis would have to be larger than for linked loci (Hastings, 1981; Hedrick, 1985).

The lack of association between the $A p$ and Lap loci in the samples from Pendine and Aberavon is in contrast with the findings of Mitton and Koehn (1973) who found significant association between the $A p$ and $L a p$ loci in an American population of Mytilus edulis and attributed it to epistatic selection. They also suggest by subdividing their sample that there was a significant environmental-genotypic interaction in the apparent epistasis between $A p$ and Lap. Perhaps the selective pressures which give rise to the nonrandom association between these enzyme loci in the American population of $M$. edulis studied by Mitton and Koehn are not operative on the coast of south Wales. In addition, it should also be mentioned that the allelic frequencies at these loci in the American population are very different from those present in the south Wales populations.

It might be useful to examine the Mitton and Koehn findings using the perspective developed by Hastings (1981). The amount of gametic disequilibrium between $A p$ and $L a p$ from Mitton and Koehn is $D=0.0246$ (Hedrick, 1983). Assuming unlinked loci $(r=0.5)$, to generate this amount of disequilibrium the relative fitnesses must vary by more than $0 \cdot 246$, given that the relative fitness of the double heterozygotes is unity (Hastings, 1981). In other words, if the selective differences were less than this amount and $r=0 \cdot 5$, the amount of disequilibrium they observed could not be generated by epistatic selection. It should be possible then to estimate directly selection coefficients of this magnitude (e.g., Hedrick and Murray, 1984) and thereby confirm or disprove the cause of disequilibrium in their population.

These results do not support the premise that structurally and functionally related enzymes are more likely to show interactions than non-related ones as suggested by Mitton and Koehn (1973) and Zouros and Krimbas (1973). However, because the randomizing effect of independent assortment is so large, making the extent of epistasis necessary to counteract it also large, stronger evidence might be obtained by comparing related versus unrelated linked enzyme loci.

\section{APPENDIX}

Various workers have used different nomenclatures for loci Ap and Lap in Mytilus. Table Al gives equivalent alleles (as we can best establish) in these different studies. Mitton and Koehn (1973) lumped rare alleles into the $s$ and $f$ electrophoretic classes. The allelic designations in Koehn et al. (1976) and Skibinski et al. (1980) indicate relative electrophoretic mobility.

Table A1 The allelic homologies at the $A p$ and Lap loci. Anodal mobility increases from top to bottom of the two charts

\begin{tabular}{|c|c|c|c|c|c|}
\hline & \multicolumn{5}{|c|}{ Reference(s) } \\
\hline & a & $\mathrm{b}$ & c & d & $e$ \\
\hline \multirow{7}{*}{$A p$} & $A p^{s}$ & $A p^{72}$ & - & - & - \\
\hline & $A p^{\prime}$ & $A p^{82}$ & 1 & 86 & 8 \\
\hline & $A p^{\prime}$ & $A p^{87}$ & 2 & 93 & 9 \\
\hline & $A p^{m}$ & $A p^{92}$ & 3 & 100 & 10 \\
\hline & $A p^{f}$ & $A p^{97}$ & 4 & 108 & 12 \\
\hline & $A p^{f}$ & $A p^{100}$ & 5 & 114 & 13 \\
\hline & $A p^{\prime}$ & $A p^{105}$ & 6 & 122 & 14 \\
\hline \multirow{5}{*}{ Lap } & $L a p^{s}$ & $\operatorname{Lap}^{92}$ & 1 & 90 & 8 \\
\hline & Laps" & $\operatorname{Lap}^{94}$ & 2 & 95 & 9 \\
\hline & $L a p^{m}$ & $\operatorname{Lap}^{96}$ & 3 & 100 & 10 \\
\hline & $L a p^{f}$ & Lap 98 & 4 & 105 & 11 \\
\hline & $L a p^{\prime}$ & $L a p^{100}$ & 5 & 110 & 12 \\
\hline
\end{tabular}

a. Mitton and Koehn (1973).

b. Koehn et al. (1976).

c. Ahmad and Beardmore (1976), Ahmad et al. (1977), present paper.

d. Skibinski et al. (1980).

e. Skibinski et al. (1983).

Acknowledgments M.A. wishes to thank J. A. Beardmore, D. O. F. Skibinski, and R. D. Ward for advice and helpful discussion during this study and to the comments of $R$. K. Koehn and several anonymous reviewers on the manuscript.

\section{REFERENCES}

AHMAD, M. AND BEARDMORE, J. A. 1976. Genetic evidence that the "Padstow mussel" is Mytilus galloprovincialis. Marine Biol, 35, 139-147. 
AHMAD, M., SKIBINSKI, D. O. F. AND BEARDMORE, J. A. 1977. An estimate of the amount of genetic variation in the common mussel, Mytilus edulis. Biochem. Genet., 15, 833846.

AHMAD, M. AND SPARKS, A. K. 1970. Chromosome number, structure and autosomal polymorphism in the marine mussels Mytilus edulis and $M$. californianus. Biol. Bull, $138,1-13$.

ENNOS, R. A. 1981. Manifold effects of the cyanogenic loci in white clover. Heredity, 46, 127-132.

EWENS, W. J. 1977. Population genetics theory in relation to the neutralist-selection controversy. Adv. Hum. Genet., 8, $67-134$.

HASTINGS, A. 1981. Disequilibrium, selection and recombination: limits in two-locus, two-allele models. Genetics, 98, $659-668$.

HEDRICK, P. W. 1983. Genetics of Populations. Jones and Bartlett, Boston.

HEDRICK, P. W. 1985. Coat variants in cats: Gametic disequilibrium between unlinked loci. J. Heredity, 76 (in press).

HEDRICK, P. W., JAIN, S. AND HOLIEN, L. 1978. Multilocus systems in evolution. Evol. Biol., 11, 101-182.

HEDRICK, P. W. AND MURRAY, E. 1983. Selection and measures of fitness, pp. 61-104, In The Genetics and Biology of Drosophilia Vol. 3d. M. Ashburner, H. L. Carson and J. N. Thompson (eds.). Academic Press, New York.

HILL, W. G. 1974. Estimation of linkage disequilibrium in randomly mating populations. Heredity, 33, 229-239.
KOEHN, R. K., MILKMAN, R. AND MitTON, J. B. 1976. Population genetics of marine pelecypods. IV. Selection, migration and genetic differentiation in the blue mussel Mytilus edulis. Evolution, 30, 2-32.

LEWONTIN, R. C. 1974. The Genetic Basis of Evolutionary Change. Columbia University Press.

MITTON, J. B. AND KOEHN, R. K. 1973. Population genetics of marine pelecypods. III. Epistasis between functionally related isoenzymes of Mytilus edulis. Genetics, 73, 487-496.

NASS, C. A. G. 1959. The $\chi^{2}$ test for small expectations in contingency tables, with special reference to accidents and absenteeism. Biometrika, 46, 365-385.

Prout, T. 1973. Appendix to Mitton, J. and Koehn, R., Population genetics of marine pelecypods. III. Epistasis between functionally related isozymes of Mytilus edulis. Genetics, $73,493-496$.

SKIBINSKI, D. O. F., BEARDMORE, J. A. AND CROSS, T. F. 1983. Aspects of population genetics of Mytilus (Mytilidae; Mollusca) in the British Isles. Biol. J. Linnean Soc., 19, 137-183. SKIBINSKI, D. O. F., CROSS, T. F. AND AHMAD, M. 1980. Electrophoretic investigation of systematic relationships in the marine mussels Modiolus modiolus L., Mytilus edulis L., and Mytilus galloprovincialis Lmk. (Mytilidae; Mollusca). Biol. J. Linnean Soc., 13, 65-73.

TURNER, J. R. G. 1972. Selection and stability in the complex polymorphism of Moraba scura. Evolution, 26, 334-343.

ZOUROS, E. AND KRIMBAS, C. B. 1973. Evidence for linkage disequilibrium maintained by selection in two natural populations of Drosophila subobscura. Genetics, 73, 659674. 